\title{
Circulating microRNA-103a-3p could be a diagnostic and prognostic biomarker for breast cancer
}

\author{
HUI LIU, QING-ZHAO BIAN, WEI ZHANG and HAI-BIN CUI \\ Department of Thyroid and Breast Surgery, Cangzhou Central Hospital, Cangzhou, Hebei 061000, P.R. China
}

Received July 26, 2021; Accepted September 15, 2021

DOI: 10.3892/ol.2021.13156

\begin{abstract}
Breast cancer (BC) is the most frequent cancer for women worldwide. Recently, a spectrum of cell-free circulating microRNAs (miR) has been recognized as promising biomarkers for $\mathrm{BC}$ diagnosis and prognosis, among which miR-103a-3p has been reported in several types of human cancer. However, the role of miR-103a-3p in BC remains unknown. A total of 112 patients with $\mathrm{BC}$ and 59 healthy controls were recruited into the present study. The expression level of serum miR-103a-3p was evaluated using reverse transcription-quantitative PCR. Receiver operating characteristic curves were utilized to calculate diagnostic accuracy. Survival curves were generated to analyze survival outcomes. It was found that circulating miR-103a-3p level was upregulated in patients with $\mathrm{BC}$ compared with that in healthy controls, and its expression was decreased following surgery. In addition, miR-103a-3p expression level was also associated with advanced clinicopathological features, including positive epidermal growth factor receptor 2 status, metastasis and an advanced TNM stage. The circulating serum miR-103a-3p level could be used to discriminate between patients with $\mathrm{BC}$ and the healthy controls prior to surgery using an area under curve [(AUC), 0.697; 95\% confidence intervals (CI), 0.615-0.778], and distinguish patients with $\mathrm{BC}$ and metastasis from those without metastasis (AUC, 0.936; 95\% CI, 0.892-0.980). In addition, high expression level of miR-103a-3p was associated with worse survival outcomes in patients with $\mathrm{BC}$. In conclusion, the present study suggests that miR-103a-3p could be a potential non-invasive diagnostic and prognostic biomarker for $\mathrm{BC}$.
\end{abstract}

\section{Introduction}

Breast cancer (BC) is the second most common malignancy worldwide and the most frequent cancer in women (1),

Correspondence to: Dr Hui Liu, Department of Thyroid and Breast Surgery, Cangzhou Central Hospital, 16 West Xinhua Road, Cangzhou, Hebei 061000, P.R. China

E-mail: Huiliu251@tom.com

Key words: miR-103a-3p, breast cancer, diagnosis, prognosis, biomarker contributing to an estimated $25 \%$ of all new cancer cases and $\sim 0.5$ million cancer-related deaths each year (2). Despite progress in the current BC therapies, including surgery, radiotherapy, chemotherapy and endocrinotherapy, almost $30 \%$ patients with $\mathrm{BC}$, diagnosed at early-stages, may develop distant metastasis, leading to death $(3,4)$. So far, a number of clinicopathological features, including tumor size, histological grade, lymph node status, hormone receptor (HR) status and human epidermal growth factor receptor type 2 (HER2) status, have been used for the diagnosis and prognostic prediction in patients with $\mathrm{BC}(5)$; however, the value of these traditional markers in predicting the prognosis of BC is limited (6). Therefore, additional diagnostic or prognostic biomarkers for early surveillance in patients with $\mathrm{BC}$ is required.

MicroRNAs (miRNAs/miR) are a family of endogenous small non-coding RNAs, which are 18-23 nucleotides in length, and are considered to regulate numerous biological processes, including cell differentiation, proliferation, apoptosis and metastasis (7-9). To date, miRNA expression signatures have been found to play a tumor suppressive or oncogenic role in cancer using translational repression or target degradation and gene silencing (10). In addition, miRNAs have been shown to be promising biomarkers for $\mathrm{BC}$ as they can be readily detected in both tumor tissues and body fluids (as circulating miRNAs), including in plasma, serum or saliva (11-13).

Numerous studies have demonstrated that miR-103a-3p is an oncomiR in various types of cancer, including thyroid cancer (14), colorectal cancer (15), gastric cancer (16), oral squamous cell carcinoma (17), malignant mesothelioma (18) and salivary adenoid cystic carcinoma (19). In contrast, Ge et al (20) reported that downregulation of miR-103a-3p could inhibit the proliferation and invasion of prostate cancer. However, the role of miR-103a-3p in BC has not been elucidated.

The aim of the present study was to detect the expression level of serum miR-103a-3p in patients with $\mathrm{BC}$, analyze the association between miR-103a-3p expression and clinicopathological features, and evaluate the ability of circulating miR-103a-3p to predict and diagnose BC.

\section{Materials and methods}

Clinical samples. A total of 112 women with BC, who were admitted and received treatment at the Cangzhou Central Hospital (Hebei, China) between January 2009 and 
December 2014 were recruited into the present study. All the patients with $\mathrm{BC}$ underwent modified radical mastectomy or breast-conserving surgery. The serum samples were collected one day prior to and following surgery. Patients were included if they were i) histologically confirmed as having invasive ductal breast carcinoma (IDC) type; ii) had no other associated malignancies; iii) had complete follow-up clinicopathological information; and iv) who were disease-free and followed up for at least 5 years. Patients with any neoadjuvant treatment prior to surgery or with bilateral or inflammatory BC were excluded. In addition, a group of 59 age- and sex-matched healthy volunteers were enrolled as a control group, at the same institution between January 2013 and December 2014, and serum samples were also obtained during routine physical examinations. The mean age was $54.1 \pm 9.8$ years for patients with BC and 53.9 \pm 9.3 years for healthy controls. The peripheral blood samples were collected from all participants in serum gel separator tubes. Each sample was centrifuged at $3,000 \mathrm{x} \mathrm{g}$ for $10 \mathrm{~min}$ at $4^{\circ} \mathrm{C}$ to separate serum, then stored at $-80^{\circ} \mathrm{C}$ until further use.

Clinical data, including age, tumor size, pathological type, lymph-node status, histological grading, metastasis and TNM stage, were also collected. The tumors were staged according to the 8th edition of the American Joint Committee on Cancer (21). Postoperative routine pathological examination, hormonal estrogen receptors (ER), progesterone receptors (PR), and HER2 were tested using immunohistochemistry by two pathologists in a blinded manner at Department of Pathology, Cangzhou Central Hospital (Cangzhou, China) independently. All enrolled patients provided written informed consent for the use of their tissue samples and clinical information in the present study. The Ethics Committee of Cangzhou Central Hospital (Hebei, China; approval no. 20210013) approved the study and was conducted in accordance with the Declaration of Helsinki.

$R N A$ extraction and reverse transcription-quantitative $P C R$ $(R T-q P C R)$. Total RNA was extracted from the prepared serum samples using the RNA Isolation kit (Qiagen, Inc.), and the cDNA was synthesized using the RevertAid First Strand cDNA Synthesis kit (Thermo Fisher Scientific, Inc.) according to the manufacturer's protocol. RT-qPCR was subsequently performed using the TaqMan miR assay system (cat. no. A25576; Applied Biosystems; Thermo Fisher Scientific, Inc.) on an FTC-3000 ${ }^{\mathrm{TM}}$ System (Funglyn Biotech Inc.). The thermocycling conditions for RT-qPCR were: Initial denaturation at $95^{\circ} \mathrm{C}$ for $1 \mathrm{~min}$, followed by 40 cycles of $95^{\circ} \mathrm{C}$ for $10 \mathrm{sec}$ and $60^{\circ} \mathrm{C}$ for $35 \mathrm{sec}$. Relative expression of miR-103a-3p was normalized to that of U6 using the $2^{-\Delta \Delta \mathrm{Cq}}$ method (22). The following primers (Shanghai GenePharma Co., Ltd) were used: miR-103a-3p forward, 5'-ATCCAGTGCGTGTCGTG-3' and reverse, 5'-TGCTAGCAGCATTGTACAGG-3'; U6 forward, 5'-CGCTTCGGCAGCACATATAC-3' and reverse, 5'-TTCACGAATTTGCGTGTCAT-3'.

Statistical analysis. The data are expressed as the mean \pm SD from at least three independent experiments. Statistical evaluations were performed using SPSS v20.0 (IBM Corp.). Differences between two groups were analyzed using an unpaired Student's t-test, while the expression of miR-103a-3p in BC serum tissues before and after surgery was compared using a paired Student's t-test. Comparisons of multiple groups were performed using ANOVA followed by Tukey's post hoc test. Categorical data were compared using either a $\chi^{2}$ test or a Fisher's exact test. Based on the median values of miR-103a-3p expression, patients with BC were classified into either miR-103a-3p low $(n=56)$ or high expression $(n=56)$ groups. Receiver operating characteristic (ROC) curves were utilized to calculate diagnostic accuracy. The survival outcomes, including overall survival (OS) and recurrence-free survival (RFS) times, were evaluated using Kaplan-Meier curves and compared using a log-rank test. OS time was calculated from the date of surgery to the date of the patient's death or to the date of last follow-up. RFS time was defined between the date of surgery to the date of $\mathrm{BC}$ recurrence. Prognostic factors were analyzed using Cox regression proportional hazards analysis. $\mathrm{P}<0.05$ was considered to indicate a statistically significant difference.

\section{Results}

Study population. As shown in Table I, 112 patients with BC were recruited into the study, and a total of 59 age-matched healthy female volunteers were used as the control group. There were $81(72.3 \%)$ patients with lymph-node involvement and 28 patients $(25.0 \%)$ with distant metastasis. With respect to TNM stage, 54 patients with BC $(48.2 \%)$ were at stage II, 30 patients $(26.8 \%)$ at stage III, and 28 patients $(25.0 \%)$ at stage IV. All other clinicopathological data are shown in Table I.

miR-103a-3p is upregulated in patients with $B C$. To primarily investigate the expression level of miR-103a-3p in BC tissues, sera from 112 patients with $\mathrm{BC}$ and 59 healthy controls were collected for RT-qPCR analysis. The results showed that miR-103a-3p expression was significantly upregulated in patients with $\mathrm{BC}$ compared with that in the controls $(\mathrm{P}<0.001$; Fig. 1A). In addition, serum miR-103a-3p expression was significantly reduced in patients with $\mathrm{BC}$ following surgery $(\mathrm{P}<0.001$; Fig. 1B). The miR-103a-3p expression level in patients with positive HER2 status was significantly higher compared with those who are HER2 negative $(\mathrm{P}<0.001$; Fig. 2A). In addition, miR-103a-3p expression level in patients with $\mathrm{BC}$ and metastasis was significantly higher compared with that in those without metastasis $(\mathrm{P}<0.001$; Fig. 2B). Comparison of miR-103a-3p expression level between patients with BC and different TNM stages showed statistically significant differences between stages II, III and IV (III vs. II, $\mathrm{P}<0.001$; IV vs. II, $\mathrm{P}<0.001$; IV vs. III, $\mathrm{P}<0.001$; Fig. 2C). Furthermore, there was no significant difference between miR-103a-3p expression levels with respect to the molecular subtypes of BC (Luminal B vs. Luminal A, $\mathrm{P}=0.732$; HER2 enriched vs. Luminal A, $\mathrm{P}=0.840$; Triple negative vs. Luminal A, $\mathrm{P}=0.501$; HER2 enriched vs. Luminal $\mathrm{B}$, $\mathrm{P}=0.667$; Triple negative vs. Luminal $\mathrm{B}, \mathrm{P}=0.341$; Triple negative vs. HER2 enriched, $\mathrm{P}=0.829$; Fig. 2D).

Association between serum miR-103a-3p expression level and clinicopathological features of $B C$. The association between the miR-103a-3p expression level and the clinicopathological features in patients with $\mathrm{BC}$ was further analyzed. It was found 
Table I. Association between miR-103a-3p expression level and clinicopathological features in patients with breast cancer.

\begin{tabular}{|c|c|c|c|c|}
\hline \multirow[b]{2}{*}{ Clinicopathological feature } & \multirow[b]{2}{*}{ Number $(n=112)$} & \multicolumn{2}{|c|}{ miR-103a-3p expression } & \multirow[b]{2}{*}{ P-value } \\
\hline & & Low $(n=56)$ & High $(n=56)$ & \\
\hline Mean age $\pm S D$, years & & $54.7 \pm 10.3$ & $53.1 \pm 9.6$ & $0.195^{\mathrm{a}}$ \\
\hline Tumor size, $\mathrm{cm}, \mathrm{n}(\%)$ & & & & $0.357^{\mathrm{b}}$ \\
\hline$\leq 2$ & $24(21.4)$ & $14(25.0)$ & $10(17.9)$ & \\
\hline$>2$ & $88(78.6)$ & $42(75.0)$ & $46(82.1)$ & \\
\hline Pathological type, n (\%) & & & & $0.844^{\mathrm{c}}$ \\
\hline IDC I & $9(8.0)$ & $5(8.9)$ & $4(7.1)$ & \\
\hline IDC II & $54(48.2)$ & $28(50.0)$ & $26(46.4)$ & \\
\hline IDC III & $49(43.8)$ & $23(41.1)$ & $26(46.4)$ & \\
\hline Lymph-node status, n (\%) & & & & $0.291^{\mathrm{b}}$ \\
\hline Negative & $31(27.7)$ & $18(32.1)$ & $13(23.2)$ & \\
\hline Positive & $81(72.3)$ & $38(67.9)$ & $43(76.8)$ & \\
\hline Histological grading, $\mathrm{n}(\%)$ & & & & $0.638^{c}$ \\
\hline I & $10(8.9)$ & $6(10.7)$ & $4(7.1)$ & \\
\hline II & $56(50.0)$ & $29(51.8)$ & $27(48.2)$ & \\
\hline III & $46(41.1)$ & $21(37.5)$ & $25(44.6)$ & \\
\hline ER, n $(\%)$ & & & & $0.686^{\mathrm{b}}$ \\
\hline Negative & $36(32.1)$ & $19(33.9)$ & $17(30.4)$ & \\
\hline Positive & $76(67.9)$ & $37(66.1)$ & $39(69.6)$ & \\
\hline PR, n (\%) & & & & $0.566^{\mathrm{b}}$ \\
\hline Negative & $47(42.0)$ & $25(44.6)$ & $22(39.3)$ & \\
\hline Positive & $65(58.0)$ & $31(55.4)$ & $34(60.7)$ & \\
\hline HER $2, \mathrm{n}(\%)$ & & & & $0.018^{\mathrm{b}}$ \\
\hline Negative & $40(35.7)$ & $26(46.4)$ & $14(25.0)$ & \\
\hline Positive & $72(64.3)$ & $30(53.6)$ & $42(75.0)$ & \\
\hline Molecular subtype $^{\mathrm{d}}, \mathrm{n}(\%)$ & & & & $0.968^{\mathrm{c}}$ \\
\hline Luminal A & $36(32.1)$ & $19(33.9)$ & $17(30.4)$ & \\
\hline Luminal B & $27(24.1)$ & $14(25.0)$ & $13(23.2)$ & \\
\hline HER2 enriched & $10(8.9)$ & $5(8.9)$ & $5(8.9)$ & \\
\hline Triple negative & $39(34.8)$ & $18(32.1)$ & $21(37.5)$ & \\
\hline Metastasis, n (\%) & & & & $0.002^{\mathrm{b}}$ \\
\hline Absent & $84(75.0)$ & $49(87.5)$ & $35(62.5)$ & \\
\hline Present & $28(25.0)$ & $7(12.5)$ & $21(37.5)$ & \\
\hline TNM stage, $\mathrm{n}(\%)$ & & & & $0.028^{\mathrm{b}}$ \\
\hline II & $54(48.2)$ & $32(57.1)$ & $22(48.2)$ & \\
\hline III & $30(26.8)$ & $16(28.6)$ & $14(26.8)$ & \\
\hline IV & $28(25.0)$ & $8(14.3)$ & $20(25.0)$ & \\
\hline
\end{tabular}

${ }^{a}$ Tested using an unpaired Student's t-test; btested using $\chi^{2}$ test; 'tested using Fisher's exact test; ' ${ }^{d}$ receptor classification. miR, microRNA; ER, estrogen receptor; PR, progesterone receptor; HER2, epidermal growth factor receptor 2; IDC, invasive ductal breast carcinoma.

that miR-103a-3p expression was significantly associated with HER2 status $(\mathrm{P}=0.018)$, metastasis $(\mathrm{P}=0.002)$ and TNM stage $(\mathrm{P}=0.028)$ (Table I).

Diagnostic value of miR-103a-3p in patients with BC. To evaluate the diagnostic value of miR-103a-3p in patients with $\mathrm{BC}$, the performance of serum miR-103a-3p level in distinguishing between patients with $\mathrm{BC}$ and the controls was performed using ROC analysis. As shown in Fig. 3A, the optimal diagnostic cut-off value for miR-103a-3p was 3.01, and the AUC value for miR-103a-3p was 0.697 [95\% confidence interval (CI), 0.615-0.778], with a sensitivity and specificity of 78.2 and $74.7 \%$, respectively. Furthermore, ROC analysis also demonstrated that the optimal diagnostic cut-off value for miR-103a-3p was 3.4, and the AUC value for miR-103a-3p was 0.936 (95\% CI, 0.892-0.980), with a sensitivity and specificity 

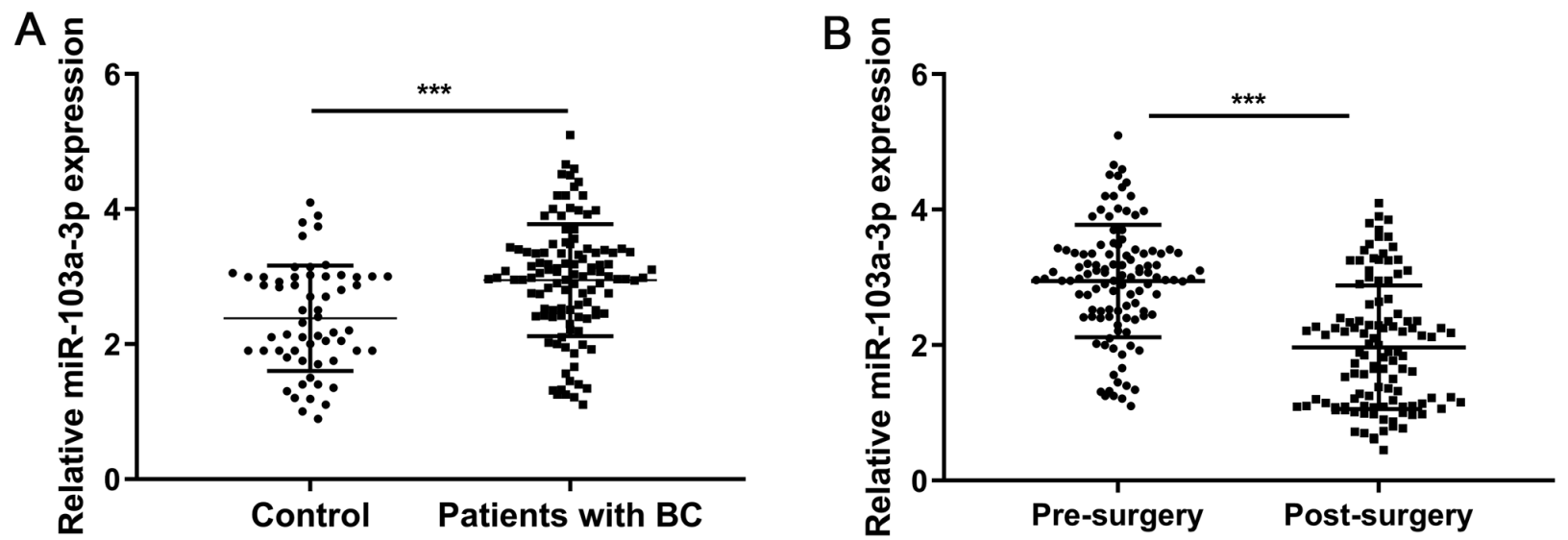

Figure 1. Upregulation of miR-103a-3p in serum from patients with BC. Reverse transcription-quantitative PCR analysis of serum miR-103a-3p expression in (A) patients with $\mathrm{BC}$ and healthy controls and in (B) patients with $\mathrm{BC}$ before and after surgery. ${ }^{* * * *} \mathrm{P}<0.001$. $\mathrm{BC}$, breast cancer; miR, microRNA.
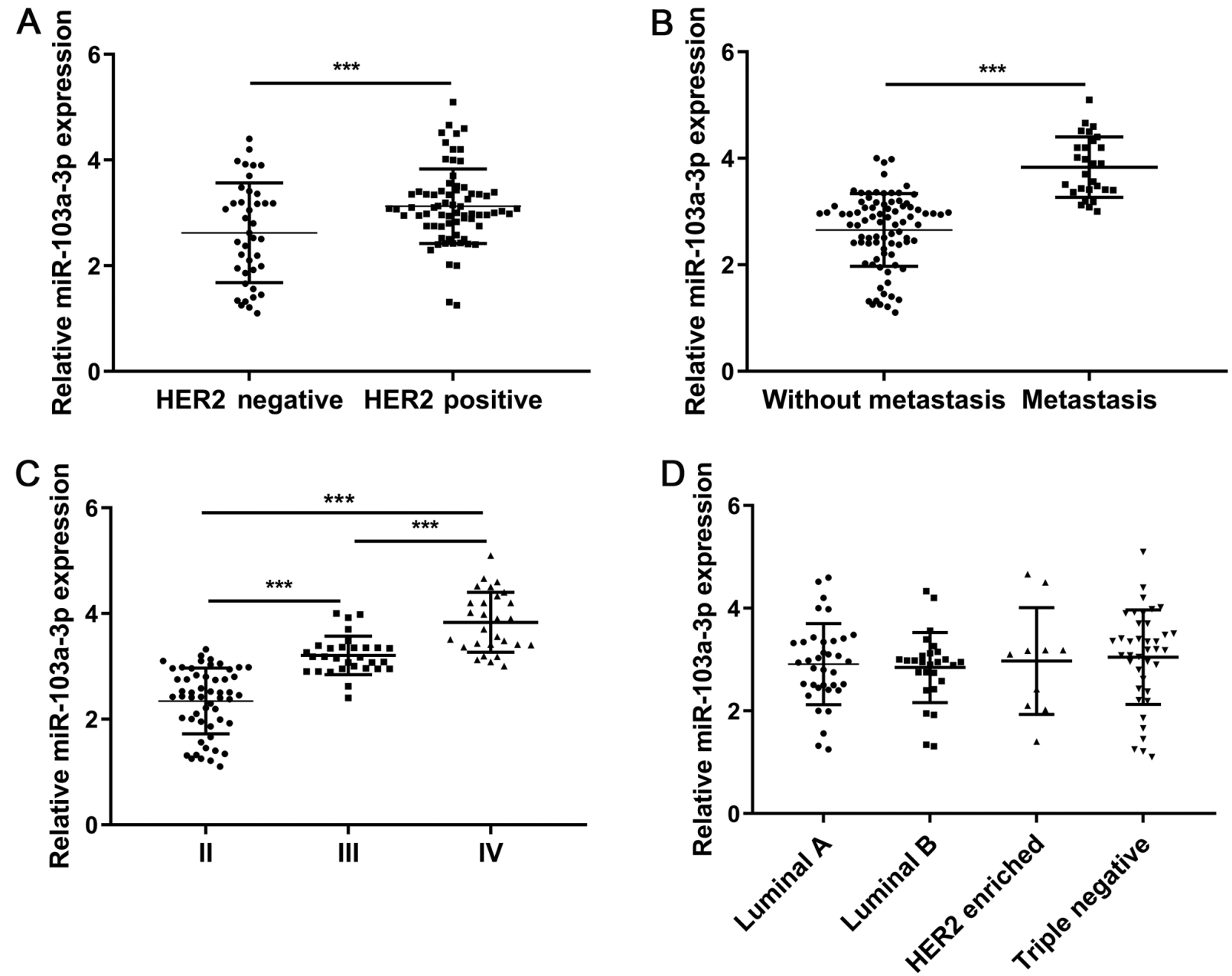

Figure 2. Reverse transcription-quantitative PCR analysis of miR-103a-3p expression in serum from patients with BC stratified by (A) HER2 status, (B) metastasis, (C) TNM stage and (D) molecular subtypes. Luminal B vs. Luminal A, P=0.732; HER2 enriched vs. Luminal A, P=0.840; Triple negative vs. Luminal A $\mathrm{P}=0.501$; HER2 enriched vs. Luminal $\mathrm{B}, \mathrm{P}=0.667$; Triple negative vs. Luminal $\mathrm{B}, \mathrm{P}=0.341$; Triple negative vs. HER2 enriched, $\mathrm{P}=0.829$. ${ }^{* * * *} \mathrm{P}<0.001$. $\mathrm{BC}$, breast cancer; miR, microRNA.

of 88.6 and $84.0 \%$, respectively, in distinguishing patients with $\mathrm{BC}$ and metastasis from those without metastasis (Fig. 3B).

Prognostic value of miR-103a-3p in patients with BC. Next, using Kaplan-Meier curves to analyze OS time, the results showed that patients with $\mathrm{BC}$ and a high expression level of miR-103a-3p was associated with worse OS ( $\mathrm{P}=0.016)$ (Fig. 4A) and RFS times $(\mathrm{P}=0.033)$ (Fig. 4B) compared with that in patients with a low expression level of miR-103a-3p. Univariate Cox regression analyses demonstrated that HER2 status 

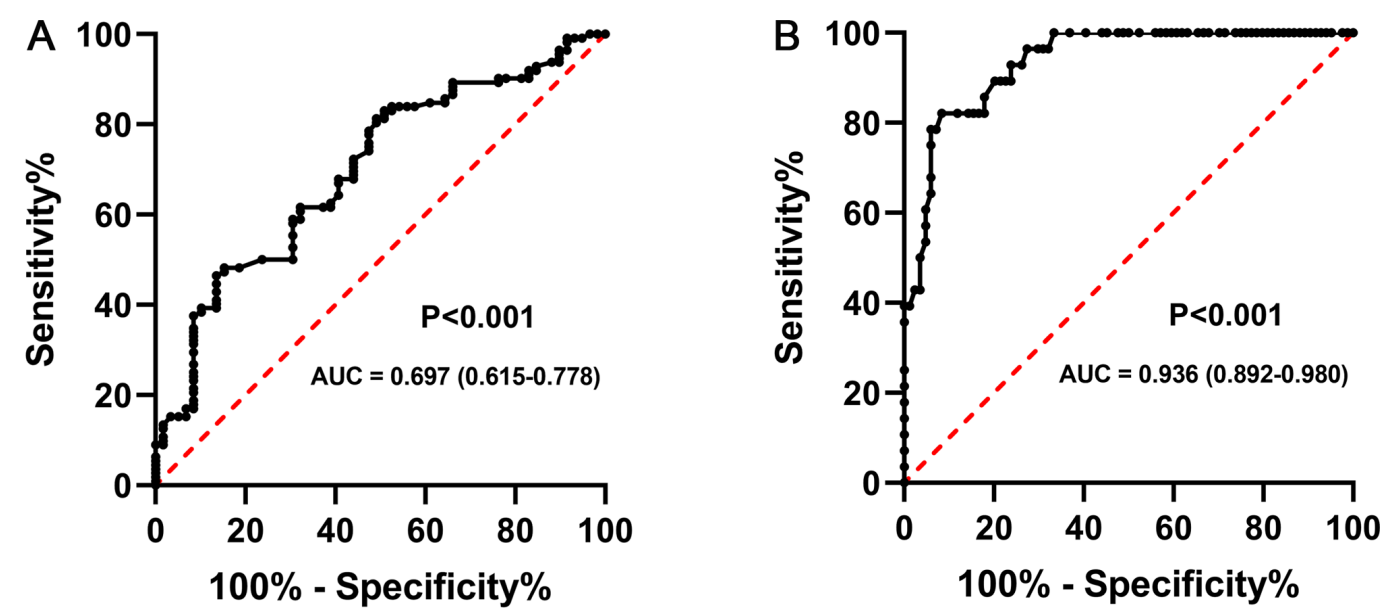

Figure 3. Diagnostic power of miR-103a-3p in patients with BC. Receiver operating characteristic curve indicates the ability of serum miR-103a-3p to distinguish between (A) patients with $\mathrm{BC}$ from the controls and (B) patients with $\mathrm{BC}$ and metastasis from patients with $\mathrm{BC}$ and without metastasis. $\mathrm{BC}$, breast cancer; AUC, area under the curve; miR, microRNA.
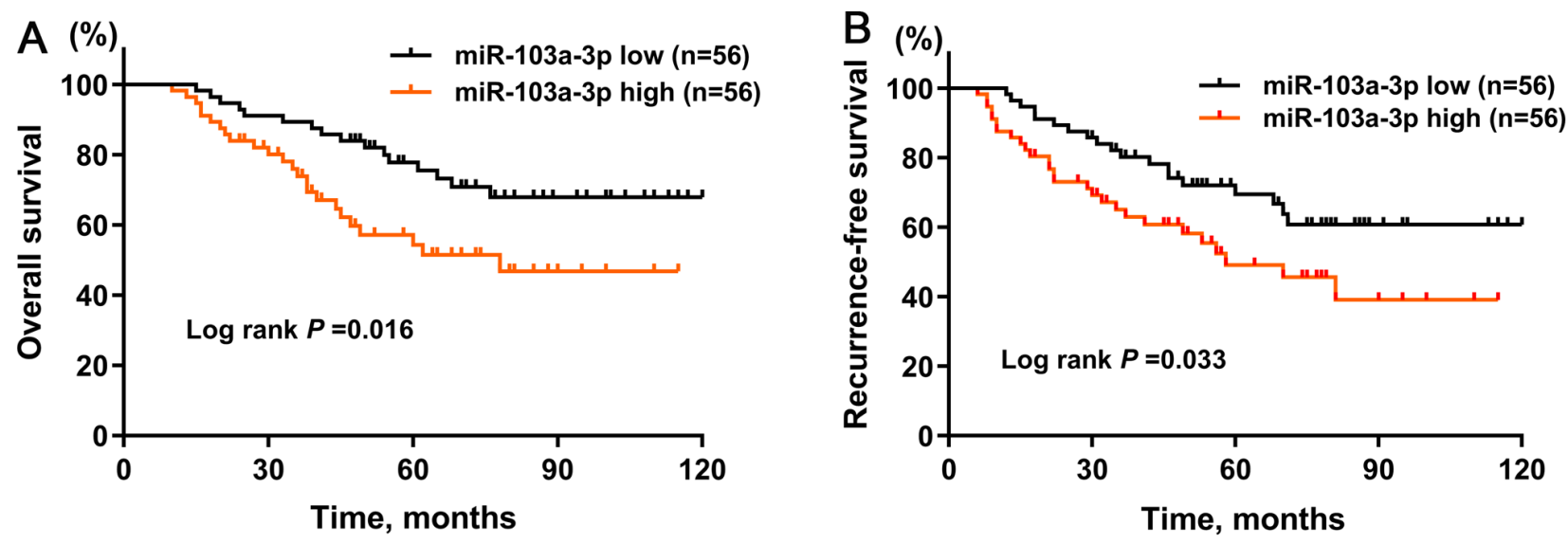

Figure 4. Prognostic power of miR-103a-3p in patients with BC. Kaplan-Meier curves of (A) overall survival and (B) recurrence-free survival in patients with BC stratified by miR-103a-3p expression level. BC, breast cancer; miR, microRNA.

[hazard ratio (HR), 2.141; 95\% CI, 1.254-3.274; $\mathrm{P}=0.002$ ), metastasis (HR, 2.841; 95\% CI, 1.542-3.984; $\mathrm{P}=0.001)$, TNM stage (III vs. II, HR, 2.547; 95\% CI, 1.564-3.854; P<0.001; and IV vs. II, HR, 2.951; 95\% CI, 1.785-3.641; P<0.001) and high miR-103a-3p expression (HR, 1.774; 95\% CI, 1.452-2.051; $\mathrm{P}=0.005$ ) were independent indicators for poor OS time in patients with BC (Table II). Multivariate Cox regression analyses showed that HER2 status [HR, 1.952; 95\% CI, 1.112-2.874; $\mathrm{P}=0.012$ ), metastasis (HR, 2.412; 95\% CI, 1.214-3.174; $\mathrm{P}=0.005$ ), TNM stage (III vs. II, HR, 2.471; 95\% CI, 1.384-3.641; P=0.001; and IV vs. II, HR, 2.814; $95 \%$ CI, 1.541-3.285; $\mathrm{P}<0.001)$ and high miR-103a-3p expression (HR, 1.612 ; $95 \%$ CI, 1.314-1.854; $\mathrm{P}=0.023$ ) were independent indicators for poor OS time in patients with BC (Table II). In addition, univariate Cox regression analyses showed that HER2 status (HR, 2.325; 95\% CI, 1.653-3.018; $\mathrm{P}=0.001$ ), metastasis (HR, 3.145; 95\% CI, 2.521-3.954; $\mathrm{P}<0.001$ ), TNM stage (III vs. II, HR, 2.154; 95\% CI, 1.621-2.963; P<0.001; and IV vs. II, HR, 2.335; 95\% CI, 1.841-3.115; $\mathrm{P}<0.001)$ and high miR-103a-3p expression (HR, 1.684; 95\% CI, 1.351-1.997; $\mathrm{P}=0.002$ ) were independent indicators for poor RFS (Table III). Multivariate Cox regression analyses revealed that HER2 status (HR,
2.010; 95\% CI; 1.532-2.991; $\mathrm{P}=0.009$ ), metastasis (HR, 2.888; 95\% CI, 2.113-3.208; $\mathrm{P}=0.001$ ), TNM stage (III vs. II, HR, 1.997; 95\% CI, 1.554-2.563; $\mathrm{P}=0.003$; and IV vs. II, HR, 2.117; 95\% CI; 1.609-3.695; $\mathrm{P}<0.001)$ and high miR-103a-3p expression (HR, 1.333; 95\% CI, 1.241-1.763; P=0.029) were independent indicators of poor RFS time (Table III). Taken together, the results indicated that miR-103a-3p was an independent unfavorable prognostic factor in patients with $\mathrm{BC}$.

\section{Discussion}

$\mathrm{BC}$ is an aggressive cancer and commonly diagnosed at a late stage, with a risk of developing metastasis (23). Recently, a spectrum of miRNAs has been determined to be of great importance during the progression of $\mathrm{BC}$, which may benefit $\mathrm{BC}$ diagnosis and prognosis (24). For example, Li et al (25) identified a panel of five plasma miRNAs (let-7b-5p, miR-122-5p, miR-146b-5p, miR-210-3p and miR-215-5p) to detect BC with high sensitivity and specificity. Zhang et al (26) screened a panel of 3 miRNAs (miR-199a, miR-29c and miR-424) for differentiating patients with $\mathrm{BC}$ from controls, with the highest diagnostic accuracy. 
Table II. Univariate and multivariate analyses of prognostic factors associated with overall survival.

\begin{tabular}{|c|c|c|c|c|}
\hline \multirow[b]{2}{*}{ Variable } & \multicolumn{2}{|c|}{ Univariate } & \multicolumn{2}{|c|}{ Multivariate } \\
\hline & HR $(95 \% \mathrm{CI})$ & P-value & $\operatorname{HR}(95 \% \mathrm{CI})$ & P-value \\
\hline Age, years & & 0.952 & & \\
\hline$\leq 50$ & Ref & & & \\
\hline$>50$ & $1.125(0.895-1.425)$ & & & \\
\hline Tumor size, $\mathrm{cm}$ & & 0.184 & & \\
\hline$\leq 2$ & Ref & & & \\
\hline$>2$ & $1.235(0.821-1.841)$ & & & \\
\hline Pathological type & & 0.115 & & \\
\hline IDC I & Ref & & & \\
\hline IDC II & $1.851(0.912-2.541)$ & 0.252 & & \\
\hline IDC III & $1.998(0.925-2.845)$ & 0.184 & & \\
\hline Lymph-node status & & 0.098 & & \\
\hline Negative & Ref & & & \\
\hline Positive & $1.965(0.841-2.862)$ & & & \\
\hline Histological grading & & 0.118 & & \\
\hline I & Ref & & & \\
\hline II & $1.541(0.852-2.415)$ & 0.102 & & \\
\hline III & $1.815(0.841-2.984)$ & 0.215 & & \\
\hline ER & & 0.521 & & \\
\hline Negative & Ref & & & \\
\hline Positive & $1.276(0.862-1.961)$ & & & \\
\hline PR & & 0.181 & & \\
\hline Negative & Ref & & & \\
\hline Positive & $1.452(0.951-1.864)$ & & & \\
\hline HER2 & & $0.002^{\mathrm{b}}$ & & $0.012^{\mathrm{b}}$ \\
\hline Negative & Ref & & Ref & \\
\hline Positive & $2.141(1.254-3.274)$ & & $1.952(1.112-2.874)$ & \\
\hline Molecular subtype ${ }^{a}$ & & 0.841 & & \\
\hline Luminal A & Ref & & & \\
\hline Luminal B & $1.241(0.865-1.874)$ & 0.546 & & \\
\hline HER2 enriched & $0.985(0.741-1.324)$ & 0.214 & & \\
\hline Triple negative & $1.141(0.741-1.685)$ & 0.623 & & \\
\hline Metastasis & & $0.001^{\mathrm{b}}$ & & $0.005^{\mathrm{b}}$ \\
\hline Absent & Ref & & Ref & \\
\hline Present & $2.841(1.542-3.984)$ & & $2.412(1.214-3.174)$ & \\
\hline TNM stage & & $<0.001^{\mathrm{b}}$ & & $<0.001^{\mathrm{b}}$ \\
\hline II & Ref & & Ref & \\
\hline III & $2.547(1.564-3.854)$ & $<0.001^{\mathrm{b}}$ & $2.471(1.384-3.641)$ & $0.001^{\mathrm{b}}$ \\
\hline IV & $2.951(1.785-3.641)$ & $<0.001^{\mathrm{b}}$ & $2.814(1.541-3.285)$ & $<0.001^{\mathrm{b}}$ \\
\hline miR-103a-3p expression & & $0.005^{\mathrm{b}}$ & & $0.023^{\mathrm{b}}$ \\
\hline Low & Ref & & Ref & \\
\hline High & $1.774(1.452-2.051)$ & & $1.612(1.314-1.854)$ & \\
\hline
\end{tabular}

${ }^{a}$ Receptor classification; ${ }^{\text {}} \mathrm{P}<0.05$. miR, microRNA; HR, hazard ratio; ER, estrogen receptor; PR, progesterone receptor; HER2, epidermal growth factor receptor 2; IDC, invasive ductal breast carcinoma.

Various studies have associated miR-103a-3p in tumor progression. As reported, miR-103a-3p expression levels were increased in gastric cancer tissues and enhanced overexpression of miR-103a-3p promoted gastric cancer cell proliferation (16). Zhang et al (14) reported that miR-103a-3p was overexpressed in thyroid cancer tissues and knocking down its expression 
Table III. Univariate and multivariate analyses of prognostic factors associated with recurrence-free survival.

\begin{tabular}{|c|c|c|c|c|}
\hline \multirow[b]{2}{*}{ Variable } & \multicolumn{2}{|c|}{ Univariate } & \multicolumn{2}{|c|}{ Multivariate } \\
\hline & HR (95\% CI) & P-value & HR $(95 \% \mathrm{CI})$ & $\mathrm{P}$-value \\
\hline Age, years & & 0.558 & & \\
\hline$\leq 50$ & Ref & & & \\
\hline$>50$ & $1.010(0.874-1.351)$ & & & \\
\hline Tumor size, cm & & 0.009 & & \\
\hline$\leq 2$ & Ref & & & \\
\hline$>2$ & $1.351(0.885-1.652)$ & & & \\
\hline Pathological type & & 0.652 & & \\
\hline IDC I & Ref & & & \\
\hline IDC II & $1.415(0.886-2.412)$ & 0.141 & & \\
\hline IDC III & $1.652(0.904-2.214)$ & 0.384 & & \\
\hline Lymph-node status & & 0.196 & & \\
\hline Negative & Ref & & & \\
\hline Positive & $1.741(0.652-2.819)$ & & & \\
\hline Histological grading & & 0.225 & & \\
\hline I & Ref & & & \\
\hline II & $1.521(0.854-1.912)$ & 0.852 & & \\
\hline III & $1.662(0.910-2.041)$ & 0.102 & & \\
\hline ER & & 0.274 & & \\
\hline Negative & Ref & & & \\
\hline Positive & $1.112(0.991-1.421)$ & & & \\
\hline PR & & 0.206 & & \\
\hline Negative & Ref & & & \\
\hline Positive & $1.352(0.928-1.657)$ & & & \\
\hline HER 2 & & $0.001^{\mathrm{b}}$ & & $0.009^{\mathrm{b}}$ \\
\hline Negative & Ref & & Ref & \\
\hline Positive & $2.325(1.653-3.018)$ & & $2.010(1.532-2.991)$ & \\
\hline Molecular subtype ${ }^{a}$ & & 0.524 & & \\
\hline Luminal A & Ref & & & \\
\hline Luminal B & $1.041(0.925-1.354)$ & 0.256 & & \\
\hline HER2 enriched & $0.912(0.825-1.319)$ & 0.741 & & \\
\hline Triple negative & $1.085(0.952-1.351)$ & 0.230 & & \\
\hline Metastasis & & $<0.001^{\mathrm{b}}$ & & $0.001^{\mathrm{b}}$ \\
\hline Absent & Ref & & Ref & \\
\hline Present & $3.145(2.521-3.954)$ & & $2.888(2.113-3.208)$ & \\
\hline TNM stage & & $<0.001^{\mathrm{b}}$ & & $<0.001^{\mathrm{b}}$ \\
\hline II & Ref & & Ref & \\
\hline III & $2.154(1.621-2.963)$ & $<0.001^{\mathrm{b}}$ & $1.997(1.554-2.563)$ & $0.003^{\mathrm{b}}$ \\
\hline IV & $2.335(1.841-3.115)$ & $<0.001^{\mathrm{b}}$ & $2.117(1.609-3.695)$ & $<0.001^{\mathrm{b}}$ \\
\hline miR-103a-3p expression & & $0.002^{\mathrm{b}}$ & & $0.029^{\mathrm{b}}$ \\
\hline Low & Ref & & Ref & \\
\hline High & $1.684(1.351-1.997)$ & & $1.333(1.241-1.763)$ & \\
\hline
\end{tabular}

${ }^{a}$ Receptor classification; ${ }^{\text {}} \mathrm{P}<0.05$. miR, microRNA; HR, hazard ratio; ER, estrogen receptor; PR, progesterone receptor; HER2, epidermal growth factor receptor 2; IDC, invasive ductal breast carcinoma.

could inhibit cell proliferation, migration and invasion, and promote thyroid cancer cell apoptosis. In addition, knocking down miR-103a-3p expression in oral squamous cell carcinoma could repress cell proliferation and induce apoptosis (17). Analysis of the clinical samples in the present study revealed that miR-103a-3p was upregulated in patients with BC and 
was also significantly associated with advanced features of $\mathrm{BC}$, including positive HER2 status, metastasis and a more advanced TNM stage. High expression of miR-103a-3p was also associated with poor survival outcomes. miR-103a-3p may represent a potential diagnostic biomarker and therapeutic target in patients with BC at different TNM stages. Notably, tumor metastasis is the main obstacle to prognosis in patients with BC. It was found that serum miR-103a-3p expression was markedly elevated in patients with $\mathrm{BC}$ and tumor metastasis, which furthers the understanding into the potential role of miR-103a-3p during BC metastasis.

Numerous studies have discussed the critical role of circulating miRNA expression as a non-invasive biomarker for early detection of numerous types of cancer (27-29), as serum samples are stable, and easily accessible for testing using RT-qPCR. However, some studies have recently reported that hemolysis during blood collection or sample processing can alter the levels of certain proposed miRNAs, such as miR-106a, miR-16 and miR-17 (30). To avoid having misleading results, it is vital to investigate whether hemolysis could affect the expression level of each miRNA in future studies. Notably, neither miR-103a-3p or U6 have been reported to be affected by hemolysis $(30,31)$. Recently, circulating miR-103a-3p has become an important area as a potential non-invasive biomarker for the diagnosis and prognosis of multiple types of cancer. For example, Zhang et al (15) established a panel of seven miRNAs in plasma, including miR-103a-3p, to predict the occurrence of colorectal cancer. In addition, Weber et al (18) demonstrated that the combination of mesothelin and miR-103a-3p in plasma could mutually enhance the diagnostic performance in the detection of malignant mesothelioma. However, the diagnostic function of miR-103a-3p has not been elucidated in BC. In the present study, the results indicated that circulating serum miR-103a-3p expression could discriminate patients with BC from control subjects prior to surgery. In addition, miR-103a-3p expression had a high ability to distinguish patients with $\mathrm{BC}$ and metastasis from those without metastasis. Traditionally, some important predictive or prognostic biomarkers, including tumor size, tumor grade, lymph node involvement, ER status and HER2 status have been used for patients with BC (32). However, tumor tissue is required for the evaluation of all the aforementioned biomarkers, which limits their clinical applications. In the present study, miR-103a-3p was detected easily and stably in peripheral blood, and could be a new prognostic and predictive marker in patients with BC. In addition, miR-103a-3p may be a potential therapeutic target in patients with $\mathrm{BC}$ due to its association with tumor metastasis and stage. For patients with $\mathrm{BC}$ and a high expression level of miR-103a-3p, more precision treatment should be utilized to reduce the rate of tumor metastasis and improve patient prognosis as well.

There are some limitations in the present study. First, there is a lack of an external cohort to validate the diagnostic and prognostic ability of miR-103a-3p. In addition, the biological role of miR-103a-3p and its underlying mechanism during BC initiation and progression remain to be clarified.

In conclusion, the results from the present study demonstrate that miR-103a-3p was upregulated in patients with $\mathrm{BC}$, and miR-103a-3p could act as a promising diagnostic and prognostic biomarker in patients with BC. Further studies are warranted to validate the diagnostic and prognostic value of miR-103a-3p with larger sample sizes, and to investigate the biological roles of miR-103a-3p in BC growth and metastasis.

\section{Acknowledgements}

Not applicable.

\section{Funding}

No funding was received.

\section{Availability of data and materials}

All data generated and/or analyzed during the study are available from the corresponding author upon reasonable request.

\section{Author's contributions}

HL and HBC conceived and designed the present study. QZB and $\mathrm{WZ}$ collected clinical samples and analyzed the data. HL and HBC wrote the manuscript. HL and HBC confirm the authenticity of all the raw data. All authors read and approved the final manuscript.

\section{Ethics approval and consent to participate}

All enrolled patients provided written informed consent for the use if their tissue samples and clinical information in the study. The Ethics Committee of Cangzhou Central Hospital (Hebei, China; approval no. 20210013) and was conducted in accordance with the Declaration of Helsinki.

\section{Patient consent for publication}

Not applicable.

\section{Competing interests}

The authors declare that they have no competing interests.

\section{References}

1. Torre LA, Bray F, Siegel RL, Ferlay J, Lortet-Tieulent J and Jemal A: Global cancer statistics, 2012. CA Cancer J Clin 65: 87-108, 2015 .

2. Siegel RL, Miller KD and Jemal A: Cancer statistics, 2016. CA Cancer J Clin 66: 7-30, 2016.

3. O'Shaughnessy J: Extending survival with chemotherapy in metastatic breast cancer. Oncologist 10 (Suppl 3): 20-29, 2005.

4. Cardoso F, Spence D, Mertz S, Corneliussen-James D, Sabelko K, Gralow J, Cardoso MJ, Peccatori F, Paonessa D, Benares A, et al: Global analysis of advanced/metastatic breast cancer: Decade report (2005-2015). Breast 39: 131-138, 2018.

5. Viale G: The current state of breast cancer classification. Ann Oncol 23 (Suppl 10): x207-x210, 2012.

6. Bertoli G, Cava C and Castiglioni I: MicroRNAs: New biomarkers for diagnosis, prognosis, therapy prediction and therapeutic tools for breast cancer. Theranostics 5: 1122-1143, 2015.

7. Tutar Y: miRNA and cancer; computational and experimental approaches. Curr Pharm Biotechnol 15: 429, 2014.

8. Mishra S, Yadav T and Rani V: Exploring miRNA based approaches in cancer diagnostics and therapeutics. Crit Rev Oncol Hematol 98: 12-23, 2016. 
9. Li B, Zhang F and Li H: miR-1225-5p inhibits non-small cell lung cancer cell proliferation, migration and invasion, and may be a prognostic biomarker. Exp Ther Med 20: 172, 2020.

10. Acunzo M, Romano G, Wernicke D and Croce CM: MicroRNA and cancer - a brief overview. Adv Biol Regul 57: 1-9, 2015.

11. Hamam R, Hamam D, Alsaleh KA, Kassem M, Zaher W, Alfayez M, Aldahmash A and Alajez NM: Circulating microRNAs in breast cancer: Novel diagnostic and prognostic biomarkers. Cell Death Dis 8: e3045, 2017.

12. Chong ZX, Yeap SK and Ho WY: Roles of circulating microRNA(s) in human breast cancer. Arch Biochem Biophys 695: 108583 , 2020.

13. Ozawa PM, Jucoski TS, Vieira E, Carvalho TM, Malheiros D and Ribeiro EM: Liquid biopsy for breast cancer using extracellular vesicles and cell-free microRNAs as biomarkers. Transl Res 223 : 40-60, 2020.

14. Zhang ML, Sun WH, Wu HQ, Liu ZD and Wang P: Knockdown of microRNA-103a-3p inhibits the malignancy of thyroid cancer cells through Hippo signaling pathway by upregulating LATS1. Neoplasma 67: 1266-1278, 2020.

15. Zhang H, Zhu M, Shan X, Zhou X, Wang T, Zhang J, Tao J, Cheng W, Chen G, Li J, et al: A panel of seven-miRNA signature in plasma as potential biomarker for colorectal cancer diagnosis. Gene 687: 246-254, 2019

16. Hu X, Miao J, Zhang M, Wang X, Wang Z, Han J, Tong D and Huang C: miRNA-103a-3p promotes human gastric cancer cell proliferation by targeting and suppressing ATF7 in vitro. Mol Cells 41: 390-400, 2018.

17. Zhang G, Chen Z, Zhang Y, Li T, Bao Y and Zhang S: Inhibition of miR-103a-3p suppresses the proliferation in oral squamous cell carcinoma cells via targeting RCAN1. Neoplasma 67: 461-472, 2020.

18. Weber DG, Casjens S, Johnen G, Bryk O, Raiko I, Pesch B, Kollmeier J, BauerTT and Brüning T: Combination of miR-103a-3p and mesothelin improves the biomarker performance of malignant mesothelioma diagnosis. PLoS One 9: e114483, 2014.

19. Fu M, Chen CW, Yang LQ, Yang WW, Du ZH, Li YR, Li SL and Ge XY: MicroRNA 103a 3p promotes metastasis by targeting TPD52 in salivary adenoid cystic carcinoma. Int $\mathbf{J}$ Oncol 57: $574-586,2020$

20. Ge J, Mao L, Xu W, Fang W, Wang N, Ye D, Dong Z, Guan H and Guan C: miR-103a-3p suppresses cell proliferation and invasion by targeting tumor protein D52 in prostate cancer. J Invest Surg 34: 984-992, 2021

21. Zhou J, Lei J, Wang J, Lian CL, Hua L, Yang LC and Wu SG: Validation of the 8th edition of the American Joint Committee on Cancer Pathological Prognostic Staging for young breast cancer patients. Aging (Albany NY) 12: 7549-7560, 2020.
22. Livak KJ and Schmittgen TD: Analysis of relative gene expression data using real-time quantitative PCR and the 2(-Delta Delta C(T)) method. Methods 25: 402-408, 2001.

23. Scully OJ, Bay BH, Yip G and Yu Y: Breast cancer metastasis. Cancer Genomics Proteomics 9: 311-320, 2012.

24. Koi Y, Tsutani Y, Nishiyama Y, Ueda D, Ibuki Y, Sasada S, Akita T, Masumoto N, Kadoya T, Yamamoto Y, et al: Predicting the presence of breast cancer using circulating small RNAs, including those in the extracellular vesicles. Cancer Sci 111: 2104-2115, 2020.

25. Li M, Zou X, Xia T, Wang T, Liu P, Zhou X, Wang S and Zhu W: A five-miRNA panel in plasma was identified for breast cancer diagnosis. Cancer Med 8: 7006-7017, 2019.

26. Zhang L, Xu Y, Jin X, Wang Z, Wu Y, Zhao D, Chen G, Li D, Wang $\mathrm{X}, \mathrm{Cao} \mathrm{H}$, et al: A circulating miRNA signature as a diagnostic biomarker for non-invasive early detection of breast cancer. Breast Cancer Res Treat 154: 423-434, 2015.

27. Valihrach L, Androvic P and Kubista M: Circulating miRNA analysis for cancer diagnostics and therapy. Mol Aspects Med 72: $100825,2020$.

28. Usuba W, Urabe F, Yamamoto Y, Matsuzaki J, Sasaki H, Ichikawa M, Takizawa S, Aoki Y, Niida S, Kato K, et al: Circulating miRNA panels for specific and early detection in bladder cancer. Cancer Sci 110: 408-419, 2019.

29. Zhu XL, Ren LF, Wang HP, Bai ZT, Zhang L, Meng WB, Zhu KX, Ding FH, Miao L, Yan J, et al: Plasma microRNAs as potential new biomarkers for early detection of early gastric cancer. World J Gastroenterol 25: 1580-1591, 2019.

30. Kirschner MB, Edelman JJ, Kao SC, Vallely MP, van Zandwijk N and Reid G: The impact of hemolysis on cell-free microRNA biomarkers. Front Genet 4: 94, 2013.

31. Iempridee T, Wiwithaphon S, Piboonprai K, Pratedrat $\mathrm{P}$, Khumkhrong P, Japrung D, Temisak S, Laiwejpithaya S, Chaopotong $\mathrm{P}$ and Dharakul T: Identification of reference genes for circulating long noncoding RNA analysis in serum of cervical cancer patients. FEBS Open Bio 8: 1844-1854, 2018.

32. Barzaman K, Karami J, Zarei Z, Hosseinzadeh A, Kazemi MH, Moradi-Kalbolandi S, Safari E and Farahmand L: Breast cancer: Biology, biomarkers, and treatments. Int Immunopharmacol 84: 106535, 2020.

(i) $(2)$ This work is licensed under a Creative Commons Attribution-NonCommercial-NoDerivatives 4.0 International (CC BY-NC-ND 4.0) License. 